\title{
Responsiveness of the innate immune system and glucose concentrations in the oldest old
}

\author{
Carolien A. Wijsman • Simon P. Mooijaart • \\ Rudi G. J. Westendorp • Andrea B. Maier
}

Received: 1 June 2011 / Accepted: 25 July 2011 /Published online: 11 August 2011

(C) The Author(s) 2011. This article is published with open access at Springerlink.com

\begin{abstract}
Patients with diabetes mellitus show increased risk of infectious disease as well as disturbances in innate immunity. In critical care settings, hyperglycemia is associated with increased risk of sepsis. It is unclear whether elevated glucose concentrations and innate immunity are associated in a nonclinical setting. We aimed to assess the association between glucose concentrations and innate immune response in the oldest old, who are at increased risk of both disturbed glucose metabolism as well as infectious disease. This study was part of the Leiden 85plus Study. In 562 subjects aged 85 years old of the general population, venous blood samples were taken for measurement of morning glucose, C-reactive protein (CRP) and glycated hemoglobin (HbA1c). The innate immune response was assessed by performing ex vivo whole blood lipopolysaccharide (LPS) stimulation for production capacity of tumor necrosis factor alpha (TNF- $\alpha$ ), interleukin 6 (IL-6), interleukin 1-beta (IL1- $\beta$ ), interleukin 10 (IL-10) and interleukin 1 receptor antagonist (IL-1Ra). Using
\end{abstract}

C. A. Wijsman $(\bowtie) \cdot$ S. P. Mooijaart

R. G. J. Westendorp · A. B. Maier

Department of Gerontology and Geriatrics,

Leiden University Medical Center,

P.O. Box 9600, 2300 RC Leiden, The Netherlands

e-mail: c.a.wijsman@lumc.nl

R. G. J. Westendorp · A. B. Maier

Netherlands Consortium of Healthy Ageing,

Leiden University Medical Center,

P.O. Box 9600, 2300 RC Leiden, The Netherlands linear regression analysis, cross-sectional analysis between glucose and cytokine production capacity was performed. We found a significant negative association between glucose concentrations, but not $\mathrm{HbA} 1 \mathrm{c}$, and cytokine response capacity in four out of five measured cytokines (all $p<0.05$ ). Both glucose and $\mathrm{HbAlc}$ were positively associated with circulating levels of CRP. Higher glucose concentrations in non-diabetic elderly are associated with lower innate immune response. As elderly show increased vulnerability for disturbances in glucose metabolism as well as infectious disease, this relation could be of clinical significance.

Keywords Aging · Glucose - Cytokine response · Innate immunity

\section{Introduction}

Patients with diabetes mellitus have a higher vulnerability for infectious diseases, which contributes to increased hospitalization and mortality (Shah and Hux 2003). It has been hypothesized that elevated glucose concentrations negatively influence cytokine production and neutrophil function (Andreasen et al. 2010; Delamaire et al. 1997). In vitro studies testing the effect of different glucose concentrations on innate immunity have yielded conflicting results (reviewed by Geerlings and Hoepelman 1999). In healthy young subjects, induction of hyperglycemia and lipopoly- 
saccharide (LPS) stimulation in vivo did not attenuate the cytokine response (Krogh-Madsen et al. 2004). In the critical care setting, detrimental effects of hyperglycemia have been shown in non-diabetic patients, where stress-induced hyperglycemia is related to higher risk of sepsis and increased morbidity and mortality (Van den Berghe et al. 2001)

In the oldest old both infectious disease and disturbances of glucose homeostasis are highly prevalent. In the present study we tested the relationship between innate immunity and glucose concentrations in non-acutely diseased community-dwelling 85 -year-olds without diabetes mellitus.

\section{Methods}

The Leiden 85-plus Study is a prospective, observational, population-based follow-up study of all inhabitants aged 85 years in Leiden, The Netherlands. Subjects were enrolled between 1997 and 1999. All participants were aged 85 years. There were no exclusion criteria. Of the 705 eligible subjects, 599 subjects were willing to participate $(87 \%)$. At baseline, non-fasted venous blood samples were obtained in the morning (before 11:00 AM) of all participants.
Ex vivo whole blood LPS stimulation was performed in 562 subjects. Levels of tumor necrosis factor alpha (TNF- $\alpha$ ), interleukin 6 (IL-6), interleukin 1-beta (IL1- $\beta$ ), interleukin 10 (IL-10) and interleukin 1 receptor antagonist (IL-1Ra) were determined $24 \mathrm{~h}$ after incubation with LPS, as more extensively described earlier (Van der Linden et al. 1998). Non-fasted plasma glucose concentrations, glycated hemoglobin (HbAlc) and C-reactive protein (CRP) levels were measured in 559 subjects. Subjects with known diabetes $(n=52)$ or hyperglycemia (non-fasted glucose $>11 \mathrm{mmol} / \mathrm{l}, n=39$ ) were excluded from analysis. Analyses were done using linear regression with adjustment for gender using SPSS version 16.0.

\section{Results}

Figure 1 shows the relation between quartiles of glucose and cytokine levels in response to LPSstimulation in 468 participants. After adjustment for gender, concentrations of non-fasted glucose correlated negatively with TNF- $\alpha$, IL-6, IL-1 $\beta$, and IL-10 (all $p$ for trend $<0.05$ ), but not with IL-1Ra ( $p$ for trend= 0.73 ). Additionally excluding the subjects with glycated hemoglobin $>6.5 \%(n=20)$ did not alter results
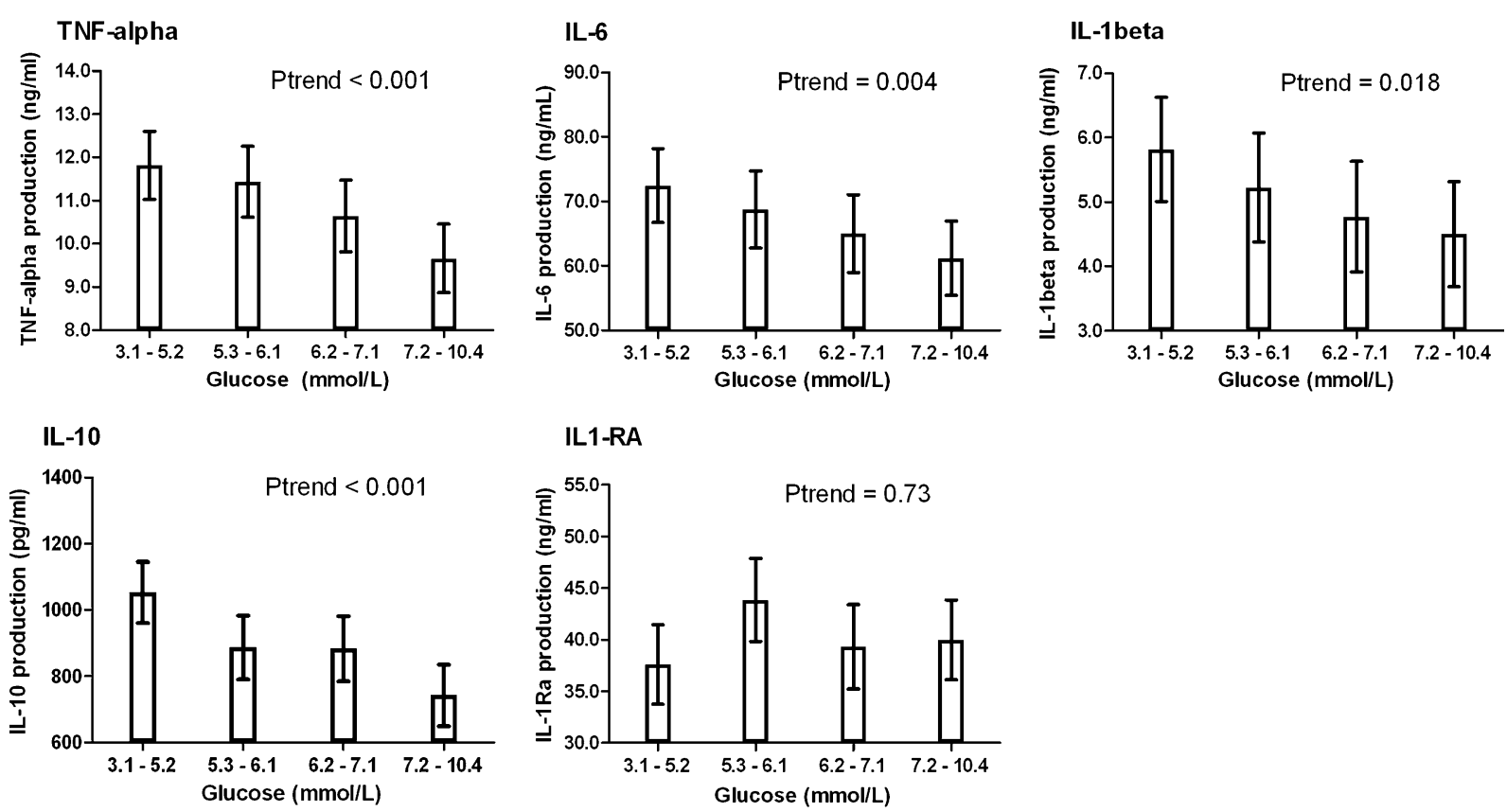

\section{IL1-RA}

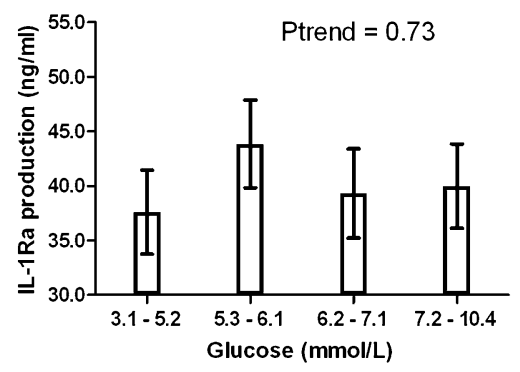

Fig. 1 Cytokine production after LPS-stimulation ex vivo by glucose concentration $(n=468)$. Cytokine data represent geometric means $\pm 95 \%$ confidence intervals, after linear regression with adjustment for gender 
(data not shown). Glucose concentrations were positively associated with CRP ( $p$ for trend=0.02).

To assess whether the association between innate immunity and glucose concentrations was affected by acute or long-term regulation of glucose metabolism, we repeated the analyses of stimulated cytokine levels dependent on $\mathrm{HbAlc}$. No consistent linear association was found between $\mathrm{HbAlc}$ and cytokines levels in response to LPS-stimulation (data not shown). HbA1c did correlate positively with CRP levels $(p=0.001)$

\section{Discussion}

We found a strong negative association between nonfasted glucose concentrations, but not HbA1c levels, and cytokine production upon LPS stimulation ex vivo in a community-dwelling, non-diabetic population of the oldest old. Both non-fasted glucose concentrations and $\mathrm{HbAlc}$ showed a positive correlation with CRP levels.

The observed relationship between non-fasted glucose and cytokine production capacity in non-diabetic subjects suggests that alterations in glucose metabolism, even in non-diabetics, may attenuate innate immune response. The lack of association between $\mathrm{HbA1c}$ and cytokine levels suggests that this effect might be driven by temporarily increases of glucose rather than chronic elevations. Earlier, hyperglycemic fluctuations, rather than continuous hyperglycemia, have been associated with negative outcome in a non-diabetic population cohort (Barr et al. 2009).

The relationship between higher glucose concentrations and low cytokine response could be of clinical significance. A low cytokine response has been independently associated with morbidity and mortality in our study population of the oldest old (van den Biggelaar et al. 2004). Furthermore, a low cytokine response has been associated with detrimental outcome in patients with sepsis at the intensive care unit (Muller Kobold et al. 2000; Westendorp et al. 1997). Also in this acutely ill patient cohort, innate immune response related inversely to levels of inflammation, such as CRP (Tschaikowsky et al. 2002).

A limitation of this study is that we did not measure insulin sensitivity. Insulin sensitivity has been associated with higher circulating inflammatory markers and is a prognostic factor for outcome in critically ill patients with myocardial infarction (Lazzeri et al. 2011; Zuliani et al. 2010). We were therefore not able to assess which mechanism of glucose metabolism is associated with innate immune function. Furthermore, as glucose concentrations were assessed at one time point only, we could also not assess glycemic variability accurately. Further studies with sensitive tools, such as continuous glucose monitoring systems, could better clarify this issue.

Importantly, our results were found in a nondiabetic population, suggesting that the blunted cytokine response is not due to specific factors related to diabetes mellitus, such as use of anti-diabetic medication, or other pathophysiological changes due to the disease, but suggest a direct relationship between glucose concentration and innate immune response. This association might be of clinical importance, as also in apparently healthy older individuals, disturbances in glucose and insulin metabolism are found such as impaired beta-cell function and decreased insulin action (Basu et al. 2003; Chang et al. 2006). Moreover, the glycemic response to stress might be increased with aging, which could further aggravate glycemic disturbances in clinical settings (Lazzeri et al. 2010; Odio and Brodish 1988).

Further studies in vivo including non-diabetic subjects are warranted to identify the mechanism behind the association between glucose concentrations and innate immune response and to investigate whether results can be extended to younger populations.

Acknowledgements This work was supported by unrestricted grants from the Netherlands Organisation of Scientific Research (ZonMw), the Ministry of Health, Welfare, and Sports and the Netherlands Genomics Initiative/Netherlands Organization for scientific research (NGI/NWO; 05040202 and 050-060-810 NCHA) and the EU funded Network of Excellence Lifespan (FP6 036894).

Open Access This article is distributed under the terms of the Creative Commons Attribution Noncommercial License which permits any noncommercial use, distribution, and reproduction in any medium, provided the original author(s) and source are credited.

\section{References}

Andreasen AS, Pedersen-Skovsgaard T, Berg RM, Svendsen KD, Feldt-Rasmussen B, Pedersen BK et al (2010) Type 2 diabetes mellitus is associated with impaired cytokine 
response and adhesion molecule expression in human endotoxemia. Intensive Care Med 36(9):1548-1555

Barr EL, Boyko EJ, Zimmet PZ, Wolfe R, Tonkin AM, Shaw JE (2009) Continuous relationships between non-diabetic hyperglycaemia and both cardiovascular disease and allcause mortality: the Australian Diabetes, Obesity, and Lifestyle (AusDiab) study. Diabetologia 52:415-424

Basu R, Breda E, Oberg AL, Powell CC, Dalla MC, Basu A et al (2003) Mechanisms of the age-associated deterioration in glucose tolerance: contribution of alterations in insulin secretion, action, and clearance. Diabetes 52:1738-1748

Chang AM, Smith MJ, Galecki AT, Bloem CJ, Halter JB (2006) Impaired beta-cell function in human aging: response to nicotinic acid-induced insulin resistance. J Clin Endocrinol Metab 91:3303-3309

Delamaire M, Maugendre D, Moreno M, Le Goff MC, Allannic H, Genetet B (1997) Impaired leucocyte functions in diabetic patients. Diabet Med 14:29-34

Geerlings SE, Hoepelman AI (1999) Immune dysfunction in patients with diabetes mellitus (DM). FEMS Immunol Med Microbiol 26:259-265

Krogh-Madsen R, Moller K, Dela F, Kronborg G, Jauffred S, Pedersen BK (2004) Effect of hyperglycemia and hyperinsulinemia on the response of IL-6, TNF-alpha, and FFAs to low-dose endotoxemia in humans. Am $\mathrm{J}$ Physiol Endocrinol Metab 286:E766-E772

Lazzeri C, Valente S, Chiostri M, Picariello C, Gensini GF (2010) Acute glucose dysmetabolism in the early phase of ST-elevation myocardial infarction: the age response. Diabetes Vasc Dis Res 7:131-137

Lazzeri C, Valente S, Chiostri M, Picariello C, Gensini GF (2011) Acute glucose dysmetabolism in the elderly with ST elevation myocardial infarction submitted to mechanical revascularization. Int J Cardiol

Muller Kobold AC, Tulleken JE, Zijlstra JG, Sluiter W, Hermans J, Kallenberg CG et al (2000) Leukocyte activation in sepsis; correlations with disease state and mortality. Intensive Care Med 26:883-892

Odio MR, Brodish A (1988) Effects of age on metabolic responses to acute and chronic stress. Am J Physiol 254: E617-E624

Shah BR, Hux JE (2003) Quantifying the risk of infectious diseases for people with diabetes. Diabetes Care 26:510-513

Tschaikowsky K, Hedwig-Geissing M, Schiele A, Bremer F, Schywalsky M, Schuttler J (2002) Coincidence of pro- and anti-inflammatory responses in the early phase of severe sepsis: longitudinal study of mononuclear histocompatibility leukocyte antigen-DR expression, procalcitonin, Creactive protein, and changes in T-cell subsets in septic and postoperative patients. Crit Care Med 30:1015-1023

Van den Berghe G, Wouters P, Weekers F, Verwaest C, Bruyninckx F, Schetz M et al (2001) Intensive insulin therapy in the critically ill patients. $\mathrm{N}$ Engl J Med 345:1359-1367

Van den Biggelaar AH, Huizinga TW, de Craen AJ, Gussekloo J, Heijmans BT, Frolich M et al (2004) Impaired innate immunity predicts frailty in old age. The Leiden 85-plus study. Exp Gerontol 39:1407-1414

Van der Linden MW, Huizinga TW, Stoeken DJ, Sturk A, Westendorp RG (1998) Determination of tumour necrosis factor-alpha and interleukin-10 production in a whole blood stimulation system: assessment of laboratory error and individual variation. J Immunol Methods 218:63-71

Westendorp RG, Langermans JA, Huizinga TW, Elouali AH, Verweij CL, Boomsma DI et al (1997) Genetic influence on cytokine production and fatal meningococcal disease. Lancet 349:170-173

Zuliani G, Galvani M, Maggio M, Volpato S, Bandinelli S, Corsi AM et al (2010) Plasma soluble gp130 levels are increased in older subjects with metabolic syndrome. The role of insulin resistance. Atherosclerosis 213:319-324 